\title{
Short Note \\ The Surface Wave Magnitude for the 9 October 2006 North Korean Nuclear Explosion
}

\author{
by Jessie Bonner, Robert B. Herrmann, David Harkrider, and Michael Pasyanos
}

\begin{abstract}
Surface waves were generated by the North Korean nuclear explosion of 9 October 2006 and were recorded at epicentral distances up to $34^{\circ}$, from which we estimated a surface wave magnitude $\left(M_{\mathrm{s}}\right)$ of 2.94 with an interstation standard deviation of 0.17 magnitude units. The International Data Center estimated a body-wave magnitude $\left(m_{\mathrm{b}}\right)$ of 4.1 . This is the only explosion we have analyzed that was not easily screened as an explosion based on the differences between the $M_{\mathrm{s}}$ and $m_{\mathrm{b}}$ estimates. Additionally, this $M_{\mathrm{s}}$ predicts a yield, based on empirical $M_{\mathrm{s}} /$ yield relationships, that is almost an order of magnitude larger than the $0.5-1 \mathrm{kt}$ reported for this explosion. We investigate how emplacement medium effects on surface wave moment and magnitude may have contributed to the yield discrepancy.
\end{abstract}

\section{Introduction}

Accurate estimation of yields for underground nuclear explosions remains an important problem for the nuclear test verification community. This was particularly evident during the days immediately following the announced nuclear test conducted by the Democratic People's Republic of Korea on 9 October 2006 at 0135 UTC. The Washington Times (13 October 2006) reported that the North Koreans told Chinese officials they were planning to conduct a $4 \mathrm{kt}$ test. After the test was conducted, the yields reported in the media ranged from as small as $0.2 \mathrm{kt}$ to as large as $15 \mathrm{kt}$ based on analyses from different sources. On 16 October 2006, the Office of the Director of National Intelligence (2006) issued a statement declaring "Analysis of air samples collected on October 11, 2006 detected radioactive debris which confirms that North Korea conducted an underground nuclear explosion in the vicinity of P'unggye on October 9, 2006. The explosion yield was less than a kiloton."

There are numerous seismic techniques currently used to estimate the yield $(Y)$ of a nuclear explosion, including using body waves (Nuttli, 1986, 1988; Patton, 1988; Vergino and Mensing, 1989; Ringdahl et al., 1992; Murphy and Barker, 2001) and scattered coda waves (Mitchell, 1991; K. R. Murphy et al., unpublished manuscript, 2007). For example, Walter et al. (2007) showed that the regional $P$-wave source spectra for the North Korean (NK) explosion suggested an explosion of $0.5 \mathrm{kt}$ at $100 \mathrm{~m}$ depth. J. R. Murphy (personal comm., 2006) estimated $1 \mathrm{kt}$ using teleseismic networkaverage $P$-wave spectra, while Kværna et al. (2007) used body-wave magnitude $\left(m_{\mathrm{b}}\right)$ /yield relations to estimate a yield between 0.5 and $1 \mathrm{kt}$. Kim and Richards (2007) also estimate the yield at $0.6 \mathrm{kt}$ based on an $m_{\mathrm{b}} /$ yield relationship.
Surface wave magnitudes $\left(M_{\mathrm{s}}\right)$ have also been used to estimate the yields of underground nuclear explosions (Marshall et al., 1979; Bache, 1982; Sykes and Cifuentes, 1984; Woods and Harkrider, 1995; Stevens and Murphy, 2001). Bache (1982) reported that $M_{\mathrm{s}} / \log Y$ relationships should provide accurate results for large events; however, increased uncertainty in the estimated yields was possible due to Rayleigh-wave radiation patterns associated with tectonic release and secondary source effects from explosions. An additional problem for smaller explosions was that fewer $M_{\mathrm{s}}$ observations would be available to estimate the yields.

Bonner et al. (2003) showed that surface wave magnitude estimation at a $7 \mathrm{sec}$ period, instead of the conventional $17-23 \mathrm{sec}$ period range, could increase the number of $M_{\mathrm{s}} \mathrm{ob}-$ servations for small events at regional distances. These results led to the development of a time-domain method for measuring surface waves (Russell, 2006) with minimum digital processing using zero-phase Butterworth filters at regional and teleseismic distances. The method can effectively measure surface wave magnitudes at variable periods between 8 and $25 \mathrm{sec}$. For applications over typical continental crusts, the magnitude equation is

$$
\begin{aligned}
M_{\mathrm{s}(\mathrm{b})}= & \log \left(a_{b}\right)+\frac{1}{2} \log [\sin (\Delta)]+0.0031\left(\frac{20}{T}\right)^{1.8} \Delta \\
& -0.66 \log \left(\frac{20}{T}\right)-\log \left(f_{c}\right)-0.43,
\end{aligned}
$$

where $a_{b}$ is the amplitude of the Butterworth-filtered surface waves (zero-to-peak in nanometers) and $f_{c} \leq 0.6 / T \sqrt{\Delta}$ is 
the filter frequency of a phaseless Butterworth band-pass filter with corner frequencies $1 / T-f_{c}$ and $1 / T+f_{c}$. At the reference period $T=20 \mathrm{sec}$, the equation is equivalent to von Seggern's formula (von Seggern, 1977) scaled to the Vanĕk et al. (1962) formula at $50^{\circ}$. For periods $8 \leq T \leq 25 \mathrm{sec}$, the equation is corrected to $T=20 \mathrm{sec}$ to account for source effects, attenuation, and dispersion. Bonner, Russell, et al. (2006) refer to this technique as $M_{\mathrm{s}}$ (VMAX), for variableperiod, maximum amplitude magnitude estimates.

There are several advantages to the $M_{\mathrm{s}}$ (VMAX) method. First, the technique allows for time-domain measurements of surface wave amplitudes, giving an analyst the ability to visually identify the phase of interest. It also allows for surface wave magnitudes to be measured at some local and regional distances where traditional $20 \mathrm{sec}$ magnitudes cannot be used. And the local and regional distance magnitude estimates are not biased with respect to teleseismic estimates using the $M_{\mathrm{s}}(\mathrm{VMAX})$ measurement technique. Additionally, the application of narrowband Butterworth-filtering techniques appropriately handles Airy phase phenomena that, prior to this technique, had to be accounted for using Marshall and Basham's (1972) empirical path corrections. Finally, because the method is variable period and is not restricted to near a $20 \mathrm{sec}$ period, the analyst is allowed to measure $M_{\mathrm{S}}$ where the signal is largest.

We have applied the $M_{\mathrm{s}}(\mathrm{VMAX})$ measurement technique to the surface waves generated by the 9 October 2006 NK nuclear test. In the following sections of this manuscript, we present the data used to estimate a network surface wave magnitude. This estimate is then compared to the $m_{\mathrm{b}}$ and used to estimate a yield based on empirical $M_{\mathrm{s}} / \log (Y)$ relationships.

\section{Analysis}

\section{Data}

The Incorporated Research Institutions in Seismology (IRIS) dedicated a data download page to the 9 October 2006 NK event (see the Data and Resources section). The data were corrected for the instrument response and converted to displacement in nanometers. Data from the Korean Seismic Research Station (KSRS) were obtained from the U.S. National Data Center and were corrected to displacement using the frequency-amplitude-response file. The horizontal components were rotated into radial and transverse waveforms. Examples of the data for three stations are shown in Figure 1. At these distances, there are large amplitude Rayleigh-wave arrivals observed on the radial and vertical components. There was no significant Love-wave energy in the surface wave analysis window.

\section{Magnitude Estimation}

The results of the $M_{\mathrm{s}}$ (VMAX) analysis for seismic stations within $34^{\circ}$ of the NK event are summarized in Figure 2 and Table 1 . We are confident that Rayleigh waves were ob-
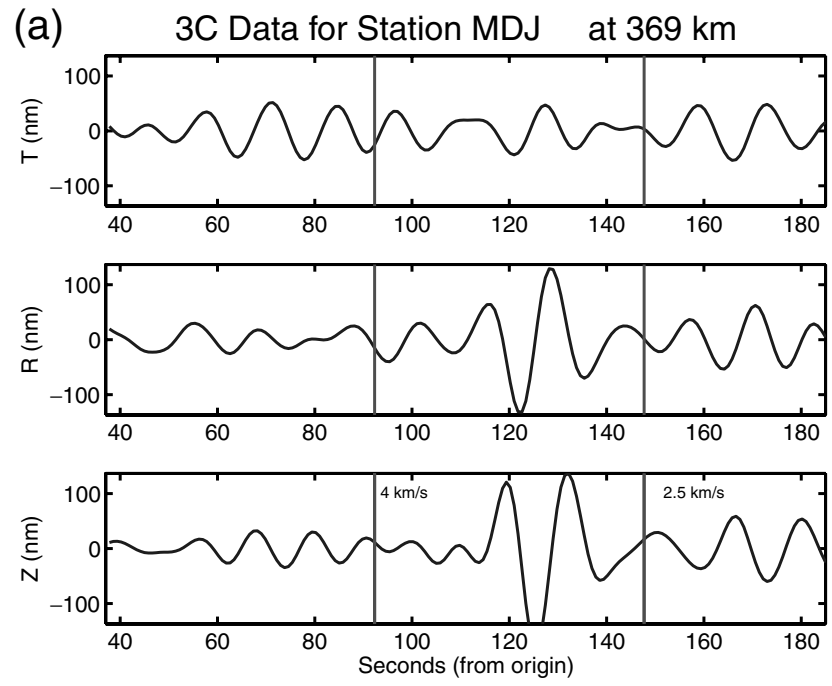

(b) 3C Data for Station BJT at $1103 \mathrm{~km}$
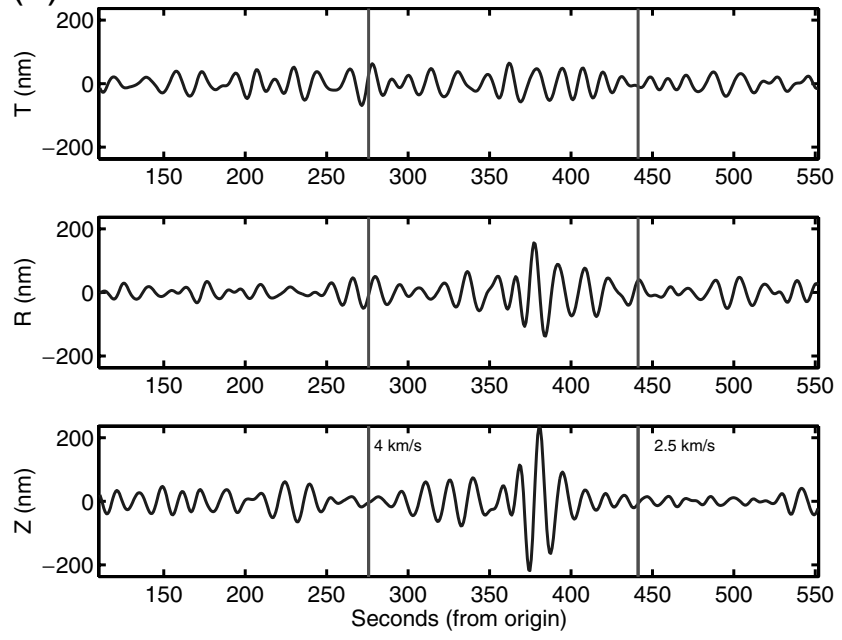

(c) 3C Data for Station ENH at $2148 \mathrm{~km}$
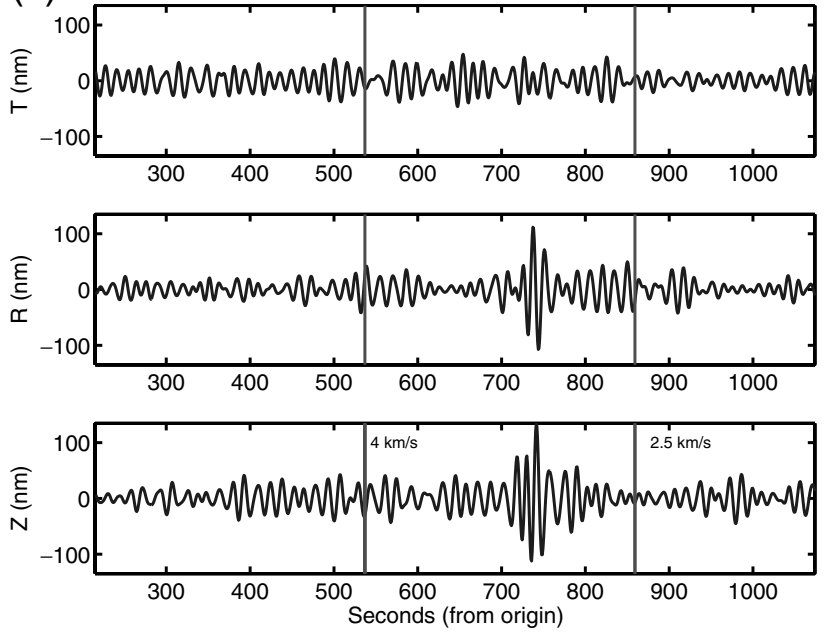

Figure 1. Three-component recordings of surface waves recorded from the 9 October $2006 \mathrm{NK}$ event. The waveforms have been rotated to provide the transverse, radial, and vertical components at stations (a) MDJ, (b) BJT, and (c) ENH. The vertical lines in each subplot represent surface wave analysis group velocity windows of 4.0 and $2.5 \mathrm{~km} / \mathrm{sec}$. 
(a)

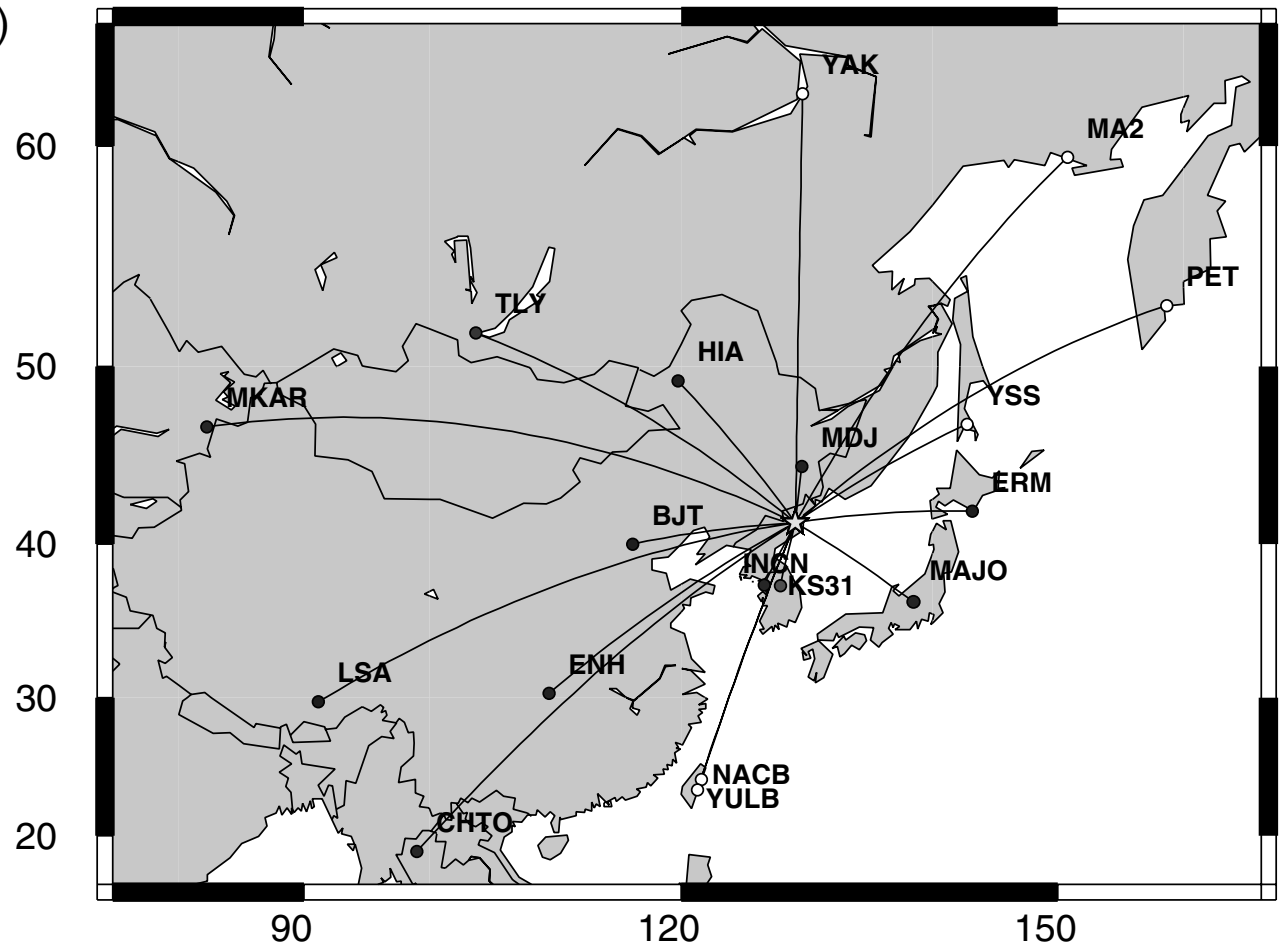

(b)

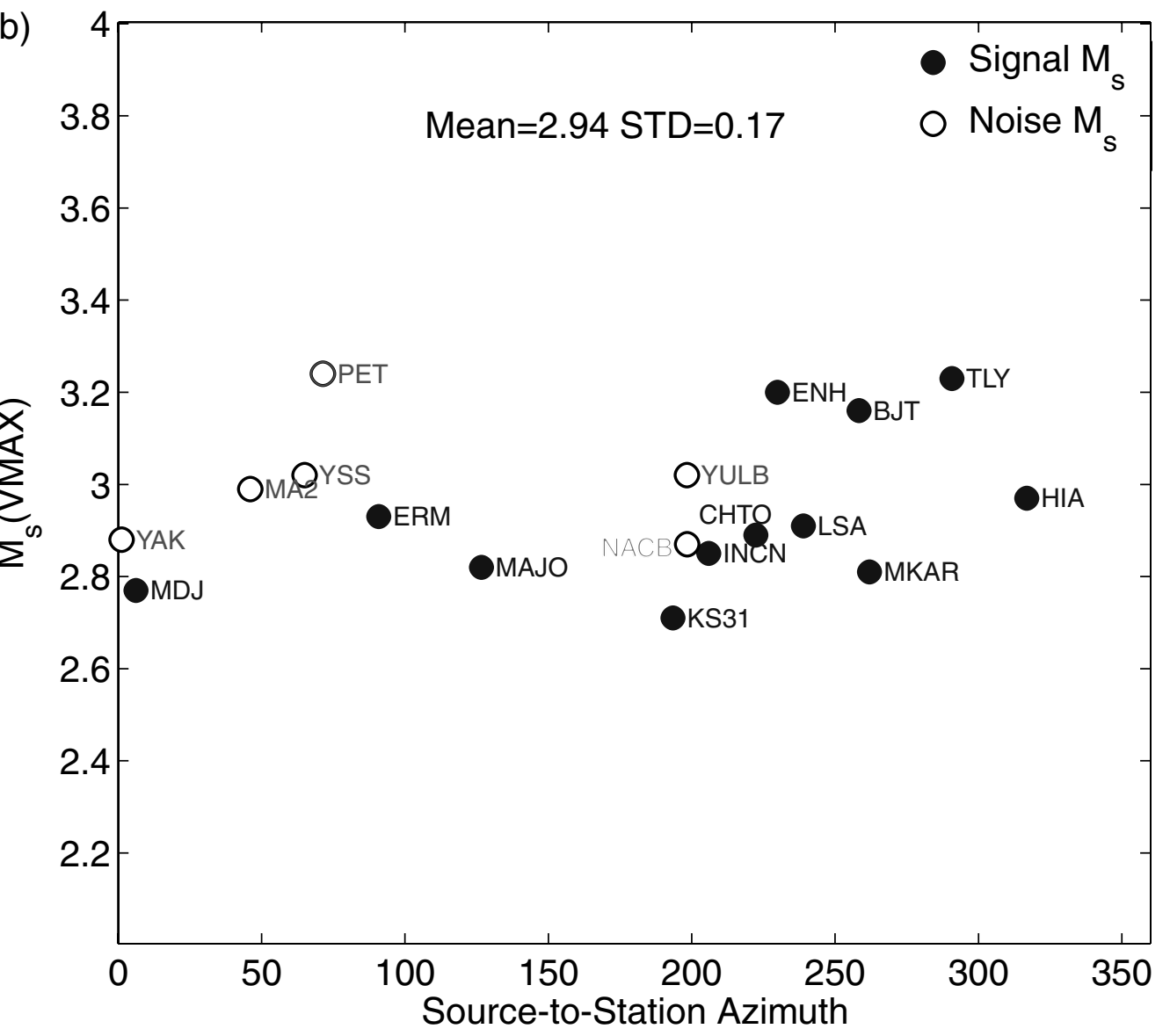

Figure 2. Signal- and noise-based $M_{\mathrm{s}}(\mathrm{VMAX})$ estimates for the NK nuclear test. (a) Map of stations showing where noise-based (open circles) and signal-based (solid circles) surface wave magnitudes were estimated. (b) Station magnitudes show a network average of 2.94, which considers only signal-based (solid circle) measurements. 
Table 1

$M_{\mathrm{s}}$ (VMAX) Results for the 9 October 2006 North Korean Event

\begin{tabular}{cccc}
\hline Station & Distance $(\mathrm{deg})$ & Period & $M_{\mathrm{s}}$ (VMAX) \\
\hline MDJ & 3.32 & 8 & 2.77 \\
KS31 & 3.98 & 10 & 2.71 \\
INCN & 4.28 & 10 & 2.85 \\
MAJO & 8.53 & 20 & 2.82 \\
BJT & 9.92 & 12 & 3.16 \\
HIA & 10.33 & 8 & 2.97 \\
ERM & 10.53 & 11 & 2.93 \\
ENH & 19.31 & 13 & 3.2 \\
TLY & 20.26 & 15 & 3.23 \\
LSA & 32.76 & 23 & 2.91 \\
MKAR & 33.67 & 23 & 2.81 \\
CHTO & 34.14 & 20 & 2.89 \\
\hline
\end{tabular}

served at INCN, ENH, TLY, HIA, BJT, MDJ, ERM, MAJO, and KS31 based on dispersion and particle motion tests. We observed longer period (>20 sec) surface waves at MKAR, LSA, and CHTO. We were unable to identify Rayleigh waves at NACB, YULB, YAK, MA2, YSS, and PET; however, we did calculate a noise-based $M_{\mathrm{s}}(\mathrm{VMAX})$ at each of these stations (Fig. 2). The concept behind the noise-based measurement is that, had an estimate been possible at this station, it would have been smaller than the noise-based $M_{\mathrm{s}}$ (VMAX) and thus is similar to a maximum-likelihood magnitude (McLaughlin, 1988).
We estimated a mean network surface wave magnitude of 2.94 with interstation standard deviation of 0.17 magnitude units (m.u.). Selby (2007) estimated the surface wave magnitude for this event as 2.83 using the Marshall and Basham (1972) formula, which is typically 0.10 m.u. smaller than $M_{\mathrm{s}}(\mathrm{VMAX})$, as will be discussed later in this article.

We note that much of the scatter in our measurement is related to three large magnitude estimates at stations ENH, BJT, and TLY, all of which are from westerly event-to-station azimuths (see Fig. 2). While a Rayleigh-wave radiation pattern could cause this azimuth effect, there were no obvious Love waves observed above background noise levels on any of our data to corroborate anisotropic source effects. Furthermore, there are additional stations along similar azimuths (e.g., HIA, CHTO, and MKAR) that did not exhibit the increased magnitudes. Stevens et al. (2007) also found increased magnitudes at ENH, BJT, and TLY and had some success explaining the magnitudes using path corrections.

The International Data Center (IDC) reported an $m_{\mathrm{b}}$ of 4.1 for the NK event (Richards, 2007). We compared our magnitude to previous $M_{\mathrm{s}}: m_{\mathrm{b}}$ research (Bonner, Pasyanos, et al., 2006; Bonner, Russell, et al., 2006) for Eurasia and found the NK event plots slightly above the Murphy et al. (1997) event screening value, which is $M_{\mathrm{s}} 2.90$ for an IDC $m_{\mathrm{b}}$ of 4.1 (Fig. 3). The NK event is the only nuclear explosion we have analyzed with a network $M_{\mathrm{s}}(\mathrm{VMAX})$ that does not fall into the explosion population below the $M_{\mathrm{s}}: m_{\mathrm{b}}$ screening line. We do note that some mining explosions do
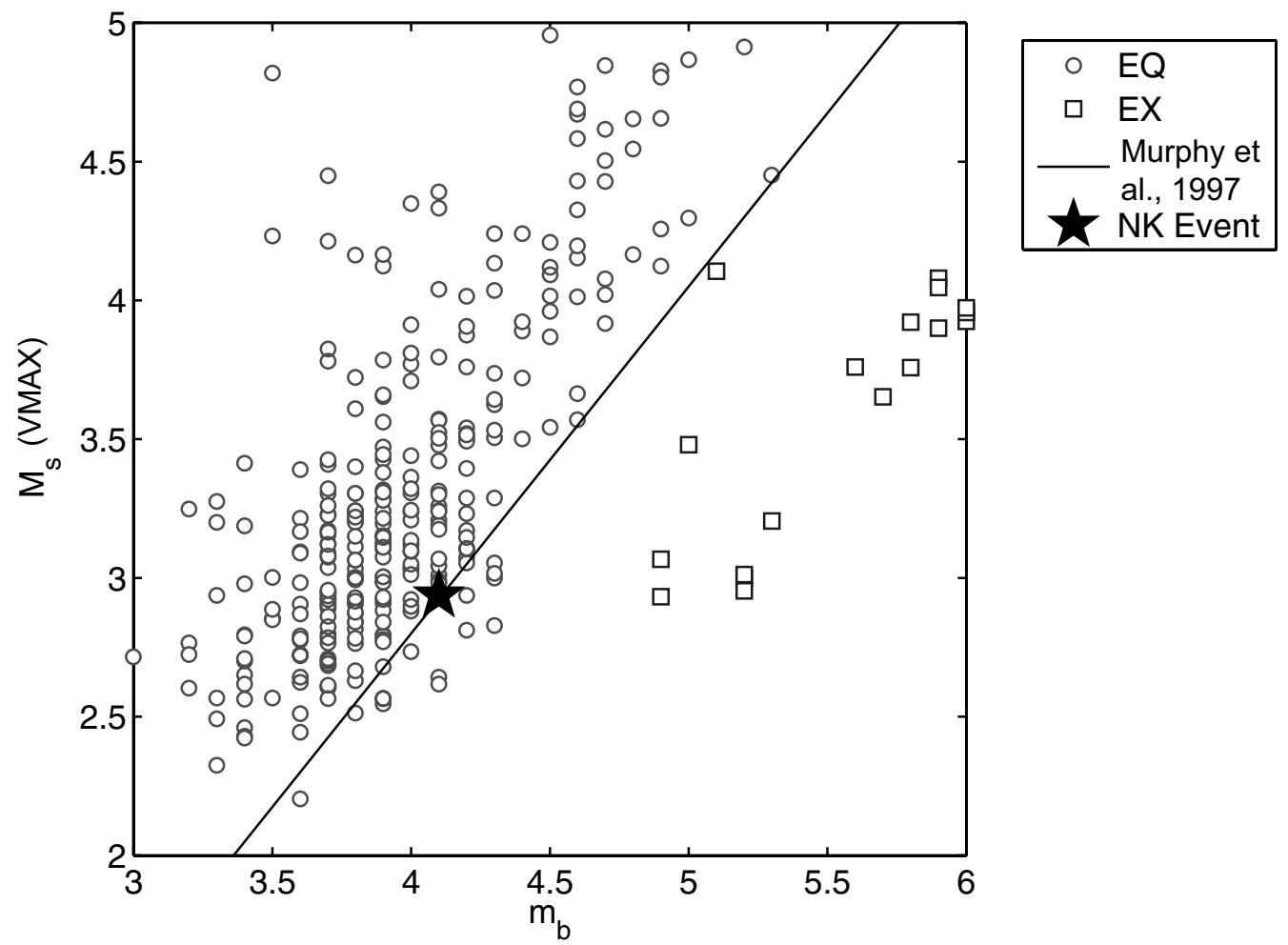

Figure 3. Network $M_{\mathrm{s}}(\mathrm{VMAX})$ estimates for earthquakes and nuclear explosions in Eurasia (from Bonner, Pasyanos, et al., 2006). The NK event is plotted as a star and falls slightly above the Murphy et al. (1997) screening line. The $m_{\mathrm{b}}$ values are from the IDC. 
not discriminate well because of the reduced $P$-wave amplitudes associated with delay-firing practices (Bonner, Pasyanos, et al., 2006). Some have suggested the NK results could be evidence of a convergence of the earthquake and explosion $M_{\mathrm{s}}: m_{\mathrm{b}}$ populations at small magnitudes (as postulated in Stevens and Day [1985]); however, Bonner, Russell, et al. (2006) saw no evidence of the convergence at the Nevada Test Site (NTS) for events of similar and smaller $m_{\mathrm{b}}$. Others have suggested this is further evidence of the need to revise the current screening criteria used for earthquake and explosion identification.

\section{Yield Estimation}

Because the 9 October 2006 event was the first nuclear explosion conducted at the NK test site, there is no calibrated empirical $M_{\mathrm{s}}$ versus yield formula that can be used to estimate the event yield. Instead, we considered a series of published $M_{\mathrm{s}} / \log Y$ relations for different test sites from previous researchers (e.g., Bache, 1982; Stevens and Murphy, 2001). While there are other similar empirical relationships in the literature (e.g., Sykes and Cifuentes, 1984; Woods, 1993), we chose Bache (1982) and Stevens and Murphy (2001) because they employed the Marshall and Basham (1972) and Rezapour and Pearce (1998) formulas, respectively, to estimate surface wave magnitudes. We have developed conversion factors that relate $M_{\mathrm{s}}(\mathrm{VMAX})$ to both formulas (Bonner, Russell, et al., 2006). For example, $M_{\mathrm{s}}$ (VMAX) estimates are on average 0.18 m.u. larger than those of Rezapour and Pearce (1998) and 0.10 m.u. larger than those of Marshall and Basham (1972). Using these values, we were able to convert the Bache (1982) and Stevens and Murphy (2001) $M_{\mathrm{s}} / \log Y$ relationships into an $M_{\mathrm{s}}$ (VMAX) $/ \log Y$ relationship (Fig. 4).

Using the $M_{\mathrm{s}}(\mathrm{VMAX}) / \log Y$ relationships in Figure 4 and the $M_{\mathrm{s}}(\mathrm{VMAX})$ estimated for the NK nuclear test, we find a range of yields between 3 and $10 \mathrm{kt}$. The median yield is $5.6 \mathrm{kt}$. These yields are significantly larger than the subkiloton results from $P$-wave based measurements. Even if we assume the three largest $M_{\mathrm{S}}$ (VMAX) estimates (ENH, BHT, and TLY) are enhanced by unmodeled path effects and subsequently remove them from our analysis, our median yield estimate is reduced to $4.5 \mathrm{kt}$.

\section{Discussion and Conclusions}

The large surface wave magnitude estimated for the NK explosion results in a yield estimate that is not in agreement with results from $P$-wave studies. The $M_{\mathrm{s}}(\mathrm{VMAX})$ for the NK event is also greater than expected when compared with earthquakes in the region of similar moment. We estimated $M_{\mathrm{s}}$ (VMAX) for 28 earthquakes occurring on or near the Korean Peninsula using local and regional seismic data and then regressed the results (Fig. 5) against moments estimated by

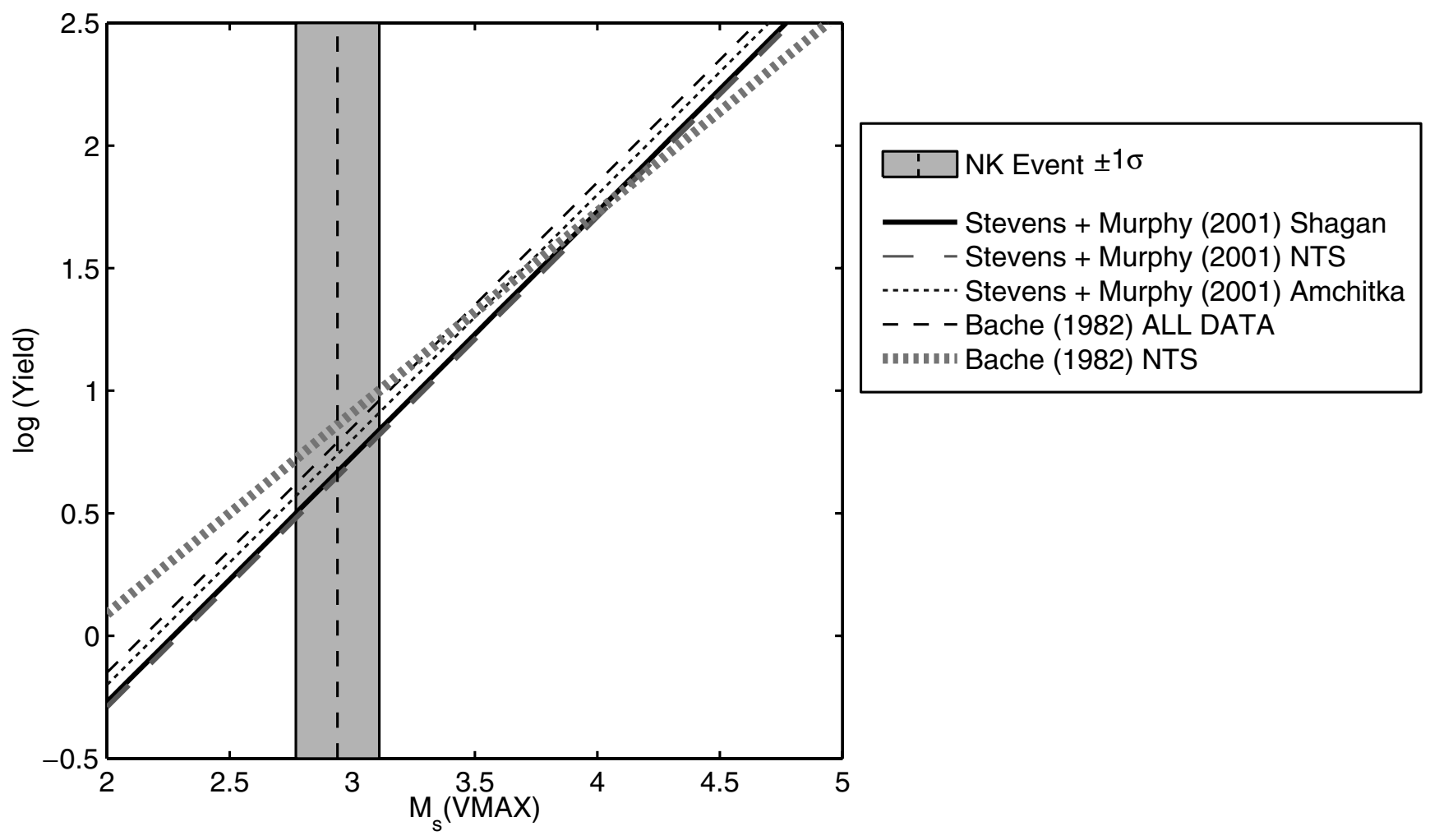

Figure 4. $\quad M_{\mathrm{s}} / \log Y$ relationships for different nuclear test sites. The Bache (1982) and Stevens and Murphy (2001) relationships were calibrated to $M_{\mathrm{s}}(\mathrm{VMAX})$ using correction terms estimated in Bonner, Russell, et al. (2006). The gray region represents the estimated $M_{\mathrm{s}}(\mathrm{VMAX})$ for the NK explosion $\pm 1 \sigma$. 


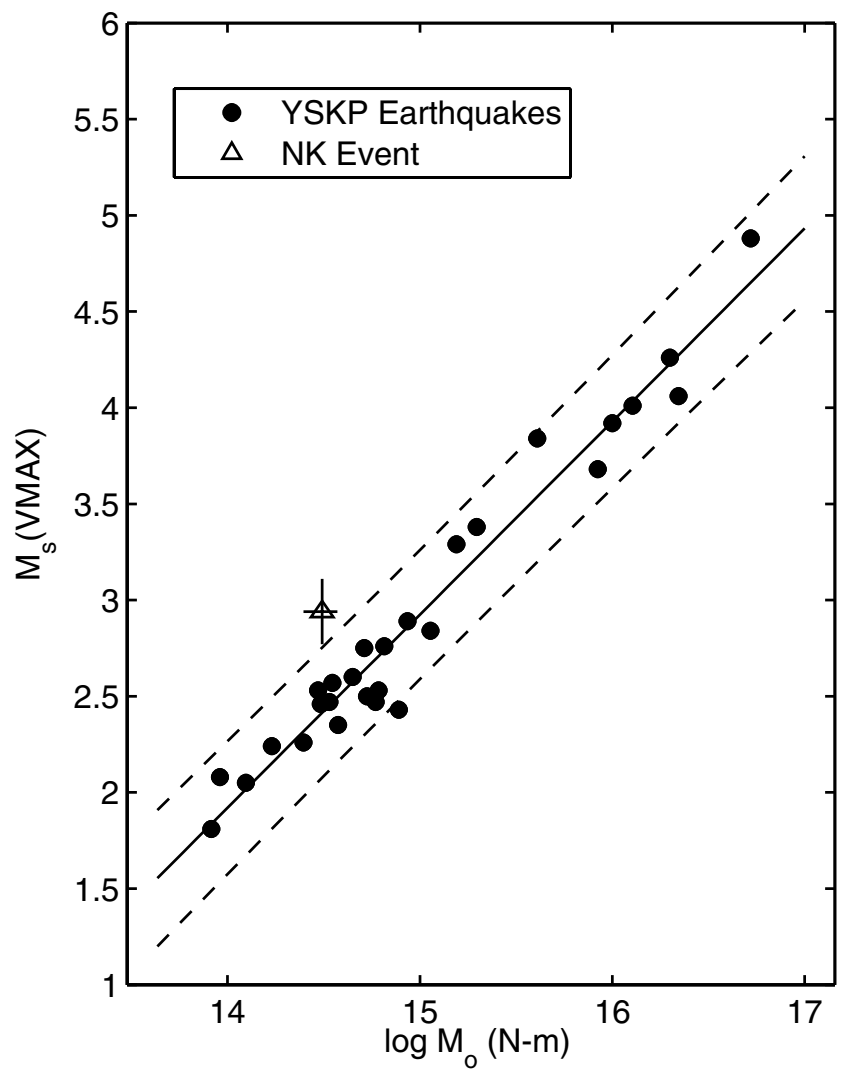

Figure 5. Regression of seismic moment versus surface wave magnitude $M_{\mathrm{S}}$ (VMAX) for earthquakes in the Yellow Sea and Korean Peninsula (YSKP) region. Also shown is the 9 October 2006 NK explosion. The solid line is the regression, while the dashed lines represent the $95 \%$ confidence band on the expected surface wave magnitude value. Error bars on the explosion data point show $\pm 1 \sigma$.

(a)

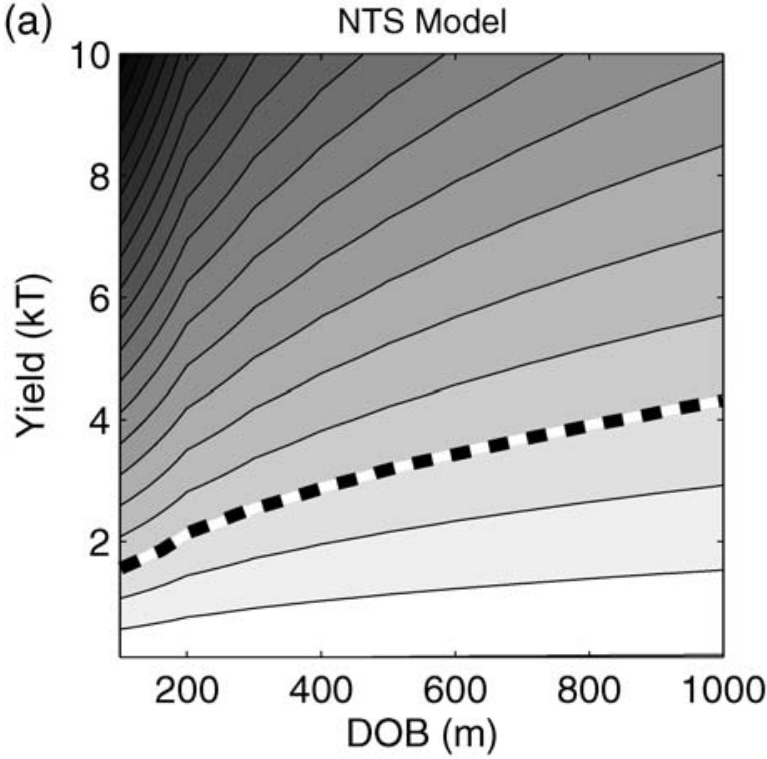

(b)

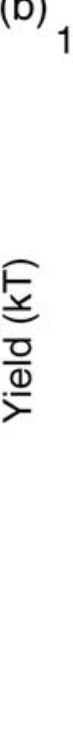

Koper et al. (2008). The $M_{\mathrm{s}}(\mathrm{VMAX}) \pm 1 \sigma$ for the NK event falls outside of the $95 \%$ confidence band for the earthquake moment-magnitude regression. While this may be a depth effect, it is further evidence of the unique characteristics of the surface wave magnitude for this explosion. In this section, we present a scenario in which a small yield explosion in a high-velocity emplacement medium could generate a relatively large $M_{\mathrm{s}}$ estimate.

Denny and Johnson (1991) developed a model for the measured seismic moment $\left(M_{0}\right)$ of explosions:

$$
M_{0}=\frac{1}{311} M_{t} P_{o}^{0.3490} 10^{-0.0269 G P},
$$

where $G P$ is gas porosity and $P_{o}$ is overburden pressure $\left(P_{o}=\rho g h\right) . M_{t}$ is the theoretical moment and is defined as

$$
M_{t}=\frac{4}{3} \pi \rho \alpha^{2} R_{c}^{3}
$$

where $\alpha$ is the $P$-wave velocity and $R_{c}$ is the cavity radius estimated by

$$
R_{c}=\frac{1.47 \times 10^{4} Y^{1 / 3}}{\beta^{0.3848} P_{o}^{0.2625} 10^{0.0025 G P}} .
$$

From the preceding equations, we can see that the measured moment for explosions in the Denny and Johnson (1991) model depends on the $P$-wave and $S$-wave $(\beta)$ velocities and yield $(Y)$.

NTS velocities provided by Springer et al. (2002) show typical emplacement $P$-wave velocities $(\alpha)$ of $3.2 \mathrm{~km} / \mathrm{sec}$ (Pahute), $2.7 \mathrm{~km} / \mathrm{sec}$ (Rainier), $2.4 \mathrm{~km} / \mathrm{sec}$ (Yucca below

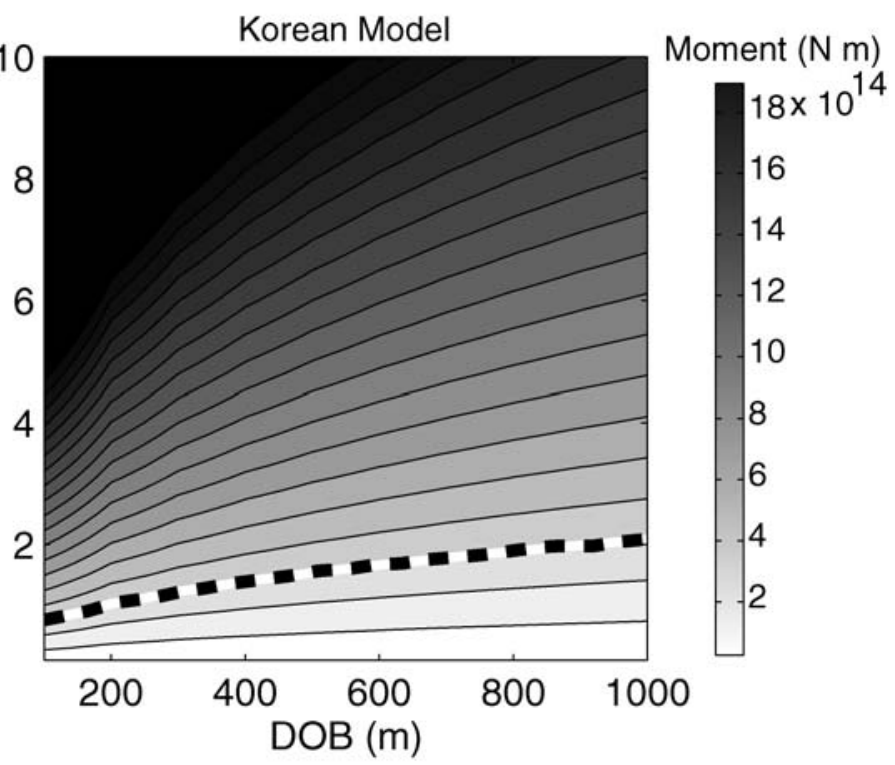

Figure 6. Estimated moments for explosions using the Denny and Johnson (1991) source model as a function of yield and depth of burial for (a) NTS and (b) Korean models. The dashed line shows the isotropic moment $\left(M_{I}=3.10( \pm 0.62) \times 10^{14} \mathrm{~N}\right.$ m) for the NK event estimated by Koper et al. (2008). 
the water table), and $1.7 \mathrm{~km} / \mathrm{sec}$ (Yucca above the water table). Ferguson (1988) suggests the NTS $S$-wave velocities $(\beta)$ are typically between $0.45 \alpha$ and $0.53 \alpha$. While similar published data do not exist for the NK test site, the Korean seismic model of Herrmann et al. (2005) suggests $P$-wave velocities in the mountainous region around the test site are $\sim 5 \mathrm{~km} / \mathrm{sec}$ with $S$-wave velocities of $\sim 3 \mathrm{~km} / \mathrm{sec}$.

We programmed the Denny and Johnson (1991) model (equations 2-4) in order to investigate the relationship between changes in the material properties, yield, and depth of burial on the seismic moment estimates. Two velocity models were considered for the upper kilometer-a generic NTS model characterized by a density of $2 \mathrm{~g} / \mathrm{cm}^{3}$, a $P$-wave velocity of $2 \mathrm{~km} / \mathrm{sec}$, and an $S$-wave velocity of $1 \mathrm{~km} / \mathrm{sec}$ and a Korean model with a density of $2.5 \mathrm{~g} / \mathrm{cm}^{3}$, a $P$-wave velocity of $5.1 \mathrm{~km} / \mathrm{sec}$, and an $S$-wave velocity of $3 \mathrm{~km} / \mathrm{sec}$. We included the NTS model because the Denny and Johnson (1991) data set consisted of many events from the NTS and it is a well-used reference model for explosions.

The moments calculated for these two models are presented in Figure 6 as a function of depth of burial and yield. Also shown is the isotropic moment $\left(M_{I}=\right.$ $\left.3.10( \pm 0.62) \times 10^{14} \mathrm{Nm}\right)$ for the NK event estimated by Koper et al. (2008). These two plots show the importance of shot emplacement media, in addition to expected depth of burial, on the surface wave moments generated from explosions with similar yields.

It is possible to convert the moments in Figure 6 to surface wave magnitudes $\left(M_{\mathrm{s}}\right)$. For example, Stevens and McLaughlin (2001) use $M_{\mathrm{s}}=\log M_{0}^{\prime}-11.74( \pm 0.21)$ to convert their path-corrected scalar moment $\left(\log M_{0}^{\prime}\right.$ in newton meters) to an $M_{\mathrm{s}}$. To convert from moment to $M_{\mathrm{S}}(\mathrm{VMAX})$, we first generated explosion synthetics using the Herrmann (2006) codes at depths between 0.1 and $1 \mathrm{~km}$ with a fixed moment and measured the resulting synthetic $M_{\mathrm{s}}(\mathrm{VMAX})$. This resulted in

$$
M_{\mathrm{s}}(\mathrm{VMAX})=\log M_{0}-11.8 \text {. }
$$

We note that the depth effects for a fixed-moment explosion in the upper $1 \mathrm{~km}$ on the surface wave magnitudes are insignificant. Secondly, we used five Asian nuclear explosions for which we had estimates of $M_{\mathrm{s}}$ (VMAX) and isotropic moment to determine a similar constant for equation (5) (e.g., 11.79 versus 11.80).

We converted the moments in Figure 6 to $M_{\mathrm{s}}(\mathrm{VMAX})$ using equation (5) and then highlighted our surface wave magnitude estimate for the NK explosion in Figure 7. We note that the yields for the NTS model and our $M_{\mathrm{s}}(\mathrm{VMAX})$ estimated yields agree with the historical data presented in Figure 4. Figure 7 predicts that for a fast velocity

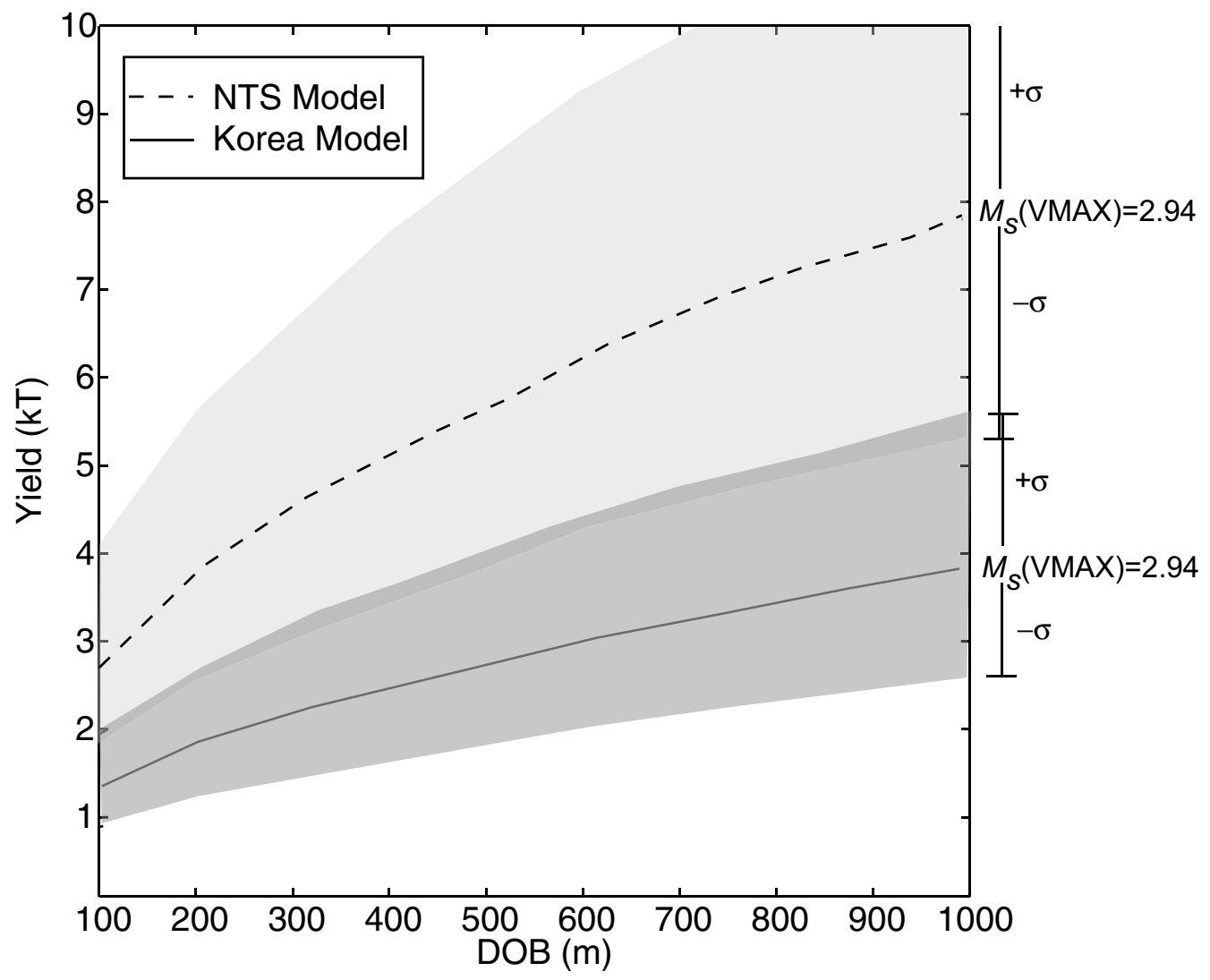

Figure 7. Yield estimates as a function of depth for the observed $M_{\mathrm{s}}(\mathrm{VMAX})$ estimate for two velocity models (NTS and Korea). The shaded regions reflect the variability due to the $\pm 1 \sigma$ on the observed magnitude. 
(e.g., hard rock) test site, it is possible for a lower yield explosion to produce larger $M_{\mathrm{s}}(\mathrm{VMAX})$ estimates than our current empirical $M_{\mathrm{s}} / \log Y$ relationships would predict. While these yield estimates are still not in the subkiloton range, they are within a factor of 2-3 of the reported yield for depths of burial less than $500 \mathrm{~m}$.

Other fast velocity test sites, such as Lop Nor (China) and Degelen Mountain (Kazakhstan), have explosiongenerated surface waves that are easily discriminated by $M_{\mathrm{s}}: m_{\mathrm{b}}$, including some of the explosions plotted in Figure 3. Thus, the fast velocity emplacement media may not be the only explanation for the inadequate $M_{\mathrm{s}}: m_{\mathrm{b}}$ screening and overestimated yield of the 9 October 2006 event. For example, Patton (2008) has postulated that the anomalous large $M_{\mathrm{s}}$ for the NK test could be due to the complete absence of tensile failure for this event.

In summary, we have determined stable surface wave magnitudes for regional earthquakes in the Korean Peninsular region and also showed the application of $M_{\mathrm{s}}(\mathrm{VMAX})$ to the NK nuclear explosion. The resulting NK magnitude was unusually large when compared with the body-wave magnitude and estimated seismic moment for the event and resulted in an overestimated yield when considering historical $M_{\mathrm{s}} / \log Y$ relationships. However, modeling the $M_{\mathrm{s}}$ using the Denny and Johnson (1991) explosion model in hard rock helped explain the overestimated yield and highlighted the importance of knowing the near-surface velocity structure when estimating the yield of buried explosions.

\section{Data and Resources}

Seismograms used in this study may be obtained from either the Incorporated Research Institutions in Seismology (IRIS) Data Management Center at www.iris.edu (last accessed July 2008) or the U.S. National Data Center at www .tt.aftac.gov (last accessed July 2008). Some plots were made using the Generic Mapping Tools version 4.2.1 (Wessel and Smith, 1998; www.soest.hawaii.edu/gmt, last accessed July 2008). Bob Herrmann's Computer Programs in Seismology (Herrmann, 2006; www.eas.slu.edu/People/RBHerrmann/ CPS330.html, last accessed July 2008) were used as part of this study.

\section{Acknowledgments}

We wish to thank Ana Stroujkova and Delaine Reiter for help acquiring some of these waveform data. Also, we have had helpful discussions with Mark Woods, Leigh House, Keith Koper, Jeff Stevens, Neil Selby, David Bowers, and Kevin Mayeda regarding manuscript preparation and the interpretation of these results. This research was sponsored by the National Nuclear Security Administration Office of Nonproliferation Research and Development and by the Office of Defense Nuclear Nonproliferation under Contract Number DE-AC52-04NA25547. This work was also performed under the auspices of the U.S. Department of Energy by Lawrence Livermore National Laboratory (LLNL) under Contract Number DE-AC52 -07NA27344. This is LLNL Contribution Number LLNL-JRNL-402269.

\section{References}

Bache, T. (1982). Estimating the yield of underground nuclear explosions, Bull. Seismol. Soc. Am. 72, S131-S168.

Bonner, J., D. Harkrider, E. T. Herrin, R. H. Shumway, S. A. Russell, and I. M. Tibuleac (2003). Evaluation of short-period, near-regional $M_{s}$ scales for the Nevada Test Site, Bull. Seismol. Soc. Am. 93, 1773-1791.

Bonner, J. L., M. Pasyanos, M. Leidig, H. Hooper, and D. Harkrider (2006). A comparison of different surface wave magnitude measurement procedures on a Eurasian dataset, in Proc. 2006 Seismic Research Review Orlando, Florida.

Bonner, J. L., D. Russell, D. Harkrider, D. Reiter, and R. Herrmann (2006). Development of a time-domain, variable-period surface wave magnitude measurement procedure for application at regional and teleseismic distances, part II: Application and $M_{s}-m_{b}$ performance, Bull. Seismol. Soc. Am. 96, 678-696.

Denny, M. D., and L. R. Johnson (1991). The explosion seismic source function: model and scaling laws revisited, in Explosion Source Phenomenology, H. J. Patton and P. G. Richards (Editors), American Geophysical Monograph 65, 1-24.

Ferguson, J. F. (1988). Body-wave magnitude variation at Yucca Flat, Nevada, Bull. Seismol. Soc. Am. 78, 863-872.

Herrmann, R. B. (2006). Computer Programs in Seismology, version 3.30, St. Louis University.

Herrmann, R. B., Y. S. Jeon, and H. J. Yoo (2005). Broadband source inversion using digital data from Korean seismic networks, in Proc. 4th International Seminar on Seismic Tomography of Far-East Asia and Related words, 2 December 2005, Korea Institute of Geoscience and Mineral Resources, Daejeon, Korea.

Kim, W. Y., and P. G. Richards (2007). North Korean nuclear explosion on 9 October 2006: a practical example of seismic discrimination at low yield (abstract), Seism. Res. Lett. 78, 253.

Koper, K., R. B. Herrmann, and H. M. Benz (2008). Overview of open seismic data from the North Korean event of 9 October 2006, Seism. Res. Lett. 79, 208-216.

Kværna, T. F., F. Ringdahl, and U. Baadshaug (2007). North Korea's nuclear test: the capability for seismic monitoring of the North Korean Test Site, Seism. Res. Lett. 78, 487-497.

Marshall, P. D., and P. W. Basham (1972). Discrimination between earthquakes and underground explosions employing an improved Ms scale, Geophys. J. R. Astron. Soc. 29, 431-458.

Marshall, P. D., D. L. Springer, and H. C. Rodean (1979). Magnitude corrections for attenuation in the upper mantle, Geophys. J. R. Astron. Soc. 57, 609-638.

McLaughlin, K. (1988). Maximum-likelihood event magnitude estimation with bootstrapping for uncertainty estimation, Bull. Seismol. Soc. Am. 78, 855-862.

Mitchell, B. J. (1991). Yield and discrimination studies in stable continental regions, final report, St. Louis University.

Murphy, J. R., and B. W. Barker (2001). Application of network-averaged teleseismic $P$-wave spectra to seismic yield estimation of underground nuclear explosions, Pure. Appl. Geophys. 158, 2123-2171.

Murphy, J. R., B. W. Barker, and M. E. Marshall (1997). Event screening at the IDC using the $M s / m b$ discriminant, final report, Maxwell Technologies. $23 \mathrm{pp}$.

Nuttli, O. (1986). Lg magnitudes of selected East Kazakhstan underground explosions, Bull. Seismol. Soc. Am. 78, 1241-1251.

Nuttli, O. (1988). $\mathrm{Lg}$ magnitudes and yield estimates for underground Novaya Zemlya nuclear explosions, Bull. Seismol. Soc. Am. 78, 873-884.

Office of the Directory of National Intelligence (2006). Statement by the Office of the Directory of National Intelligence on the North Korea nuclear test, news release, Washington, D.C.; available at http:// www.odni.gov/announcements/20061016_release.pdf (last accessed July 2008).

Patton, H. J. (1988). Application of Nuttli's method to estimate yield of Nevada Test Site explosions recorded on Lawrence Livermore Na- 
tional Laboratory's digital seismic system, Bull. Seismol. Soc. Am. 78, 1759-1772.

Patton, H. J. (2008). Implications of the CLVD on long-period seismic waves from nuclear explosions (abstract), Seism. Res. Lett. 79, no. $2,306$.

Rezapour, M., and R. G. Pearce (1998). Bias in surface-wave magnitude $M_{\mathrm{s}}$ due to inadequate distance correction, Bull. Seismol. Soc. Am. 88, 43-61.

Richards, P. (2007). Forensic seismology and CTBT verification, CTBTO Newsl. 9, 1.

Ringdahl, F., P. D. Marshall, and R. W. Alewine (1992). Seismic yield determination of Soviet underground nuclear explosions at the Shagan River test site, Geophys. J. Int. 109, 65-77.

Russell, D. R. (2006). Development of a time-domain, variable-period surface wave magnitude measurement procedure for application at regional and teleseismic distances, part I: Theory, Bull. Seismol. Soc. Am. 96, 665-677.

Selby, N. (2007). Implications of the 9 October 2006 North Korean nuclear test for event screening (abstract), Seism. Res. Lett. 78, 253.

Springer, D. L., G. A. Pawloski, J. L. Ricca, R. F. Rohrer, and D. K. Smith (2002). Seismic source summary for all U.S. below-surface nuclear explosions, Bull. Seismol. Soc. Am. 92, 1806-1840.

Stevens, J. L., and S. M. Day (1985). The physical basis of the $m_{b}: M_{s}$ and variable frequency magnitude methods for earthquake/explosion discrimination, J. Geophys. Res. 90, 3009-3020.

Stevens, J. L., and K. L. McLaughlin (2001). Optimization of surface wave identification and measurement, Pure Appl. Geophys. 158, $1547-1582$.

Stevens, J. L., and J. R. Murphy (2001). Yield Estimation from Surface-wave Amplitudes, Pure Appl. Geophys. 158, 2227-2251.

Stevens, J., J. Given, H. Xu, and G. Baker (2007). Development of Surface Wave Dispersion and Attenuation Maps and Improved Methods for Measuring Surface Waves, Proc. 29th Monitoring Research Review, 25-27 September 2007, Denver, Colorado.

Sykes, L. R., and I. L. Cifuentes (1984). Yields of Soviet underground nuclear explosions from seismic surface waves: compliance with the Threshold Test Ban Treaty, Proc. Natl. Acad. Sci. USA 81, 1922-1925.

Vanĕk, J., A. Zatopek, V. Karnik, Y. V. Riznichenko, E. F. Saverensky, S. L. Solov'ev, and N. V. Shebalin (1962). Standardization of magnitude scales, Bull. (Izvest.) Acad. Sci. U.S.S.R. Geophys. Ser. 2, 108.

Vergino, E. S., and R. W. Mensing (1989). Yield estimation using regional $m_{b}(P n)$, Report UCID-101600, Lawrence Livermore National Laboratory.

von Seggern, D. (1977). Amplitude distance relation for 20-second Rayleigh waves, Bull. Seismol. Soc. Am. 67, 405-411.
Walter, W., E. Matzel, M. Pasyanos, D. Harris, R. Gok, and S. Ford (2007). Empirical observations of earthquake-explosion discrimination using $P / S$ ratios and implications for the sources of explosion $S$-Waves, Proc. 29th Monitoring Research Review, 25-27 September 2007, Denver, Colorado.

Wessel, P., and W. H. F. Smith (1998). New, improved version of the Generic Mapping Tools released, EOS Trans. AGU 79, 579.

Woods, B. B. (1993). Regional surface wave magnitude and moment determination methods applied to nuclear explosions at the Nevada test site: implications for yield estimation and seismic discrimination, Ph.D. Thesis, California Institute of Technology; available at http:// resolver.caltech.edu/CaltechETD:etd-04212006-165925 (last accessed July 2008).

Woods, B. B., and D. G. Harkrider (1995). Determining surface-wave magnitudes from regional Nevada Test Site, Geophys. J. Int. 120, 474-498.

Weston Geophysical Corporation

4000 S. Medford, Suite 10W

Lufkin, Texas 75901

bonner@westongeophysical.com

(J.B.)

Department of Earth and Atmospheric Sciences

Saint Louis University

3642 Lindell Boulevard

St. Louis, Missouri 63108

rbh@eas.slu.edu

(R.B.H.)

Weston Geophysical Corporation 57 Bedford Street, Suite 102 Lexington, Massachusetts 02420 hark@ourconcord.net

(D.H.)

Lawrence Livermore National Laboratory

7000 East Avenue, MS L-205

Livermore, California 94551-0808

pasyanos1@1lnl.gov

(M.P.)

Manuscript received 6 February 2008 